\title{
Public Concerns Over Transgenic Crops
}

\author{
Philip J. Dale ${ }^{1}$ \\ John Innes Centre, Norwich NR4 7UH, UK
}

O ver the past 16 years it has become possible to isolate genes from any class of living organism and introduce them into most of our crop plants. This provides a wider choice of genes for crop improvement than is available by conventional plant breeding. International studies worldwide on genome organization, genetic mapping, and the isolation of genes are providing many new opportunities to modify crops. In 1999, there were almost 40 million hectares of transgenic crops grown across the world (James 1999). Although there is considerable optimism about the future prospects for transgenic crops among the scientific and plant breeding community, public concerns are being expressed in some countries. The assessment and potential impact of transgenic crops has been discussed in scientific publications and at conferences for over a decade, but now the subject is a major focus of pressure groups, with vandalism of transgenic field plots in some countries and substantial amounts of money being spent internationally on opposition. The aim of this paper is to give a perspective on current concerns.

\section{Do We Need Transgenic Crops?}

It is argued that the world has one and a half times enough food to feed its 6 billion people and that what we need is better food distribution (Simms 1999). Improved distribution is clearly a challenge for politicians and for societies generally, but do countries that are short of food really want refugee-style food handouts to feed their population in the long term? They surely aspire to selfsufficiency and food security, to be able to grow crops that resist local pests and

\footnotetext{
'E-MAIL phil.dale@bbsrc.ac.uk; FAX 44-1603456844.
}

diseases, crops that have minimal reliance on chemical inputs, and use local labor. When world population is twice its current level, nutritional needs will not be met by food redistribution; higher levels of production will be needed. Also, if we are to avoid increasing the area of land under cultivation and the erosion of more natural habitats, the current area of cultivated land will need to be more productive. Transgenic crops are not the only way to improve crop productivity, but they are likely to play an increasingly important role in world agriculture in the coming decades.

\section{What Are the Potential Benefits?}

One of the most compelling motivations for genetic modification is to improve resistance to pests and diseases. The access to novel sources of genetic resistance will provide the opportunity to reduce our dependence on chemical sprays for their control. Currently, $>30,000$ metric tons of sprays are used in the United Kingdom each year (Thomas and Wardman 1999). There are also likely to be other opportunities to reduce chemical inputs by appropriate genetic modification. A range of potential benefits is shown in Table 1.

\section{Are Transgenic Crops Safe for Food and the Environment?}

Members of the general public are often unaware of the extensive testing and evaluation necessary to produce conventionally bred crops. In addition to agricultural performance, it is often necessary to test for toxicity and other adverse effects of the crop. Conventional plant breeding is very much more sophisticated than that practiced by Men- del in his early pioneering genetics experiments. Many novel plant breeding methods have been developed and refined over this century. These include sexual hybridization with the aid of ovary and embryo culture, mutagenesis, haploidization and polyploidization (Hayward 1993; Dale 1999.

Compared with transgenic breeding, conventional breeding is very imprecise in many respects but has proved remarkably successful. This is because plant breeders have learned how to test and evaluate plants, select only those lines that have desirable characters, and reject the rest.

Modern molecular methods of genetic modification now make it possible to introduce genes into crops from a wide range of different organisms; therefore, there is international agreement that there should be an additional set of safety assessments. All of the tests from conventional breeding are practiced, plus a wide range of additional safety assessments for genetically modified crops (Dale and Irwin, 1998). These tests evaluate actual and potential impact on food, human and animal health, and the environment. With these additional safety tests, and the ability to analyze transgenes with a much greater precision than is usually possible for genes introduced by conventional breeding, I believe there is compelling evidence that genetically modified crops are as safe as conventionally bred crops.

\section{What Is the Public Concerned About?}

A number of the concerns expressed in public meetings, in the media and in publications are summarised in Table 2, along with brief responses to them. Many of these concerns are intensified in people's minds by the activity of pressure groups and the use of pejorative 


\section{Table 1. Potential Benefits of Transgenic Crops}

1. Resistance to pests and diseases.

2. Modifications in fruit ripening and tuber storage; research research in potatoes is likely to reduce dependence on antisprouting compounds.

3. Modification of oil, starch, and protein to provide sustainable supplies of raw materials for food, biodegradable plastics, detergents, lubricants, paper making, and packaging.

4. Herbicide tolerance so that crop varieties can tolerate specific herbicides and in many instances reduce the number of herbicide applications to achieve effective weed control.

5. Increased tolerance to environmental stresses including temperature, water, and saline soils.

6. Plant architecture (e.g., dwarfing) and flowering (e.g., flowering time).

7. Increase in the ability of certain plants to removing toxic metals from soils (bioremediation).

8. Reduction in seed shedding at harvest time.

9. Enhancement of vitamins, minerals, and anticancer substances (e.g., vitamin A and iron).

10. The elimination of allergens from certain crops (e.g., rice).

11. The production of pharmaceutical substances (e.g., edible vaccines).

terms such as "Frankenstein food," "gene foods," "mutant crops," and "genetic pollution." There is little doubt that there is a deliberate attempt to demonize the process of transgenic plant breeding by giving the impression that it is innately bad, flawed, undesirable, unnatural and therefore unacceptable. The pressure groups are skilled at manipulating the media, and many appear to be not interested in a careful scientific response to concerns.

Fortunately, there is a significant proportion of people in society that are genuinely seeking scientific answers to their concerns. There are important questions raised by transgenic crops, but many are also issues associated with conventional plant breeding and agriculture. Many of these concerns are not scientific but often passionately held and are probably a significant driving force in influencing opinion. The concerns include

1. Multinational companies. There is a perception that powerful multinational companies can have a significant influence on agriculture and food production. There is also the view that traditional farming practices may be undermined, for example, farmer-saved seed.

2. World trade. World trade agreements may undermine the consumer's freedom to make choices in what they buy. These choices can be made for ideological reasons but are seen to be part of an individual's democratic right.

3. Human health. A series of food scares in the United Kingdom and Europe (e.g., bovine spongiform encephalopathy, Salmonella and Escherichia coli food poisoning) have sensitized some people to the belief that food is unsafe.

4. Environment. There are concerns in some countries that agriculture is responsible for reducing wildlife biodiversity, for example, numbers of birds within certain species. These are issues about the environmental impact of agriculture generally.

\section{Why the Difference in Attitude Between North America and Europe?}

There are a number of likely reasons for this. In North America there is apparently a greater willingness to embrace new technology. It seems there is generally a greater respect for the role of industry and the profit motive in North America, whereas in Europe this is commonly viewed with a degree of suspicion. In Europe, North America is seen to be an enormously powerful trading block, with considerable muscle in world trade. Consumers want a choice in what they buy, for a variety of reasons, and become frustrated when that choice is denied (e.g., unlabeled transgenic maize and soya bean). Food in Europe is frequently an emotive subject, and attitudes tend to be conservative and traditional. Also, Europeans often have concerns about environmental matters, particularly with such a large proportion of EU land being farmed in some way.

There is a diminishing proportion of the population in developed countries that really understands the process of agricultural production, and even less that has personal experience. Within the United Kingdom particularly, there are strong feelings about the treatment of animals and it has some of the highest standards of farm animal welfare. Any suggestion that agricultural products are obtained from countries or from agricultural systems that are perceived to be less than ideal (e.g., hormone induced milk or meat) will result in some consumers actively avoiding products from those systems.

\section{What Does the Future Hold?}

I believe that genetic modification provides a very exciting future and presents plant breeders, farmers, and society with very substantial opportunities for improving crop production. There is the opportunity to reduce our dependence on chemical inputs and to improve crops in a variety of ways. However, the acceptance of transgenic crops in the long term is not simply a matter of science and market forces. It is important that as a global society, with many international links and associations, we develop our vision for the future of ag- 


\section{Table 2. Concerns Expressed During Debates on Transgenic Crops}

\section{Concerns}

1. Genes are being moved across natural sexual barriers. This is sometimes considered "unnatural" and therefore "undesirable."

2. To introduce genes by transformation disturbs the natural "genetic balance" or order.

3. It is difficult to predict the long-term impact of transgenic crops on food and the environment.

4. There may be undesirable nontarget effects on friendly organisms within the environment, e.g., monarch butterfly, lacewing, ladybirds.

5. There may be erosion of traditional practices, particularly in developing countries.

6. Patenting life (genes and organisms) for some people is unethical.

7. Substantially improved transgenic varieties may replace locally adapted varieties and landraces (genetic erosion).

8. Transgenic crops may contribute further to the intensification of agriculture and the reduction in wildlife biodiversity.

9. There may be unanticipated effects on beekeeping and honey products.

10. Pollination by transgenic crops may result in organic crops losing their organic status.

11. Crops may be produced that become superweeds or have toxic/allergenic properties.

12. Irrespective of the scientific arguments, many people would like labeling of transgenic products and therefore the opportunity for choice.

\section{Responses}

Genes can be moved across sexual barriers by conventional breeding methods (e.g., ovary and embryo culture). Many natural things are bad for us (e.g., smallpox) and many unnatural things are good (e.g., immunization against smallpox).

Mutation breeding has the potential to cause extensive changes in genetic balance and has been surprisingly successful in conventional breeding.

International methods of safety assessment are designed to assess this. It is necessary to draw on many years of experience in traditional breeding and, where necessary, the generation of novel data. Some countries are introducing long-term monitoring programs, where appropriate.

This is an important aspect of risk assessment and an area of considerable research interest. It is important to ask what the baseline is against which we compare the impact of transgenic crops. The most reasonable baseline is current agricultural practice with conventional crops.

It is very important to preserve traditional practices, such as farmer saved seeds, where they are of vital importance to local agriculture. Interestingly, hybrid rice varieties are widely used in China because of their higher yield. Farmers have to buy new seeds each year.

Often an emotive subject. For progress to be made in crop improvement, programs either have to be publicly funded and seeds made more or less freely available, or supported by private companies who need a financial return for their investment. Patents last for $\sim 15-17$ years, so in many instances a transgene patent will have $<10$ years to run when a new transgenic variety is released commercially.

This needs to be taken very seriously if we are to maintain sufficient genetic diversity in plant varieties. Transformation, however, can provide a means of inserting transgenes into locally adapted varieties without long periods of backcrossing.

Transgenic crops have the potential to aggravate or alleviate wildlife biodiversity, depending on how we use it. The ever more clinical control of pests, diseases, and weeds is likely to leave little food in the agricultural environment to support a diversity of wildlife. However, the more precise targeting of pest and disease resistance and the reduced dependence on control by sprays should favor friendly organisms in the environment and a diversity of food chains supported by them.

The expression of transgenes in pollen and the potential effect on bees and honey are taken into account during safety assessment.

The current view of the organic movement in the United Kingdom and several other countries is that "there is no place for transgenic crops in organic agriculture." Factors to take into account when considering the significance of gene flow from transgenic crops to organic crops have been reviewed recently (Moyes and Dale 1999). Transgenic crops are likely to be of great importance in the development of integrated pest and disease management systems with minimal chemical inputs.

This outcome is probably more likely in conventional breeding where several thousands of unwanted genes are transferred into crops, often from wild relatives of the crop. Undesirable effects are considered carefully in the risk assessment.

This is essentially a political and social issue. If the refined product of a transgenic and a conventionally bred variety is chemically indistinguishable, there is no good scientific reason to label. However, some consumers would like labeling and choice for ideological reasons. 
riculture, food production and the environment. We need to be sensitive to the desires of society for choice and to find mechanisms to provide that choice. Above all, we need to provide crops that are of clear benefit to the consumer (e.g., price, health, environment). If, in developing biotechnology, we pay attention to consumers, they will pay attention to its products.

\section{ACKNOWLEDGMENTS}

I thank the Biotechnology and Biological Sciences Research Council for their support and Helen Ghirardello for help in preparing the manuscript. The views expressed are personal ones and may not be those of the organizations or committees with which I am associated.

\section{REFERENCES}

Dale, P.J. 1999. Curr. Opin. Biotechnol. 10: $203-208$.

Dale P.J. and J.A. Irwin. 1998: In Transgenic plant research (ed K. Lindsey), pp. 277-285. Harwood Academic Publishers, Amsterdam, The Netherlands.

Hayward M.D, N.O. Bosemark and I. Romagosa, eds. 1993. Plant breeding. Chapman \& Hall, London, UK.

James, C. 1999. Global Review of Commercialized Transgenic Crops: 1999. ISAAA Briefs No 12: Preview.
International Service for the Acquisition of Agri-biotech Applications. Ithaca, NY.

Moyes, C.L. and P.J. Dale. 1999. Organic farming and gene transfer from genetically modified crops. MAFF (Ministry of Agriculture, Fisheries and Food) Research Project OF0157. http://www.gmissues.org/orgreport/ gmissues

Simms, A. 1999. Selling Suicide. Christian Aid. http://www.christian-aid.org.uk/ f_reports.htm

Thomas, M.R. and O.L. Wardman. 1999. Review of usage of pesticides in agriculture and horticulture throughout Great Britain 1986-1996. Pesticide Usage Survey Report 150. Ministry of Agriculture, Food and Fisheries Publication Number PB 4188. 


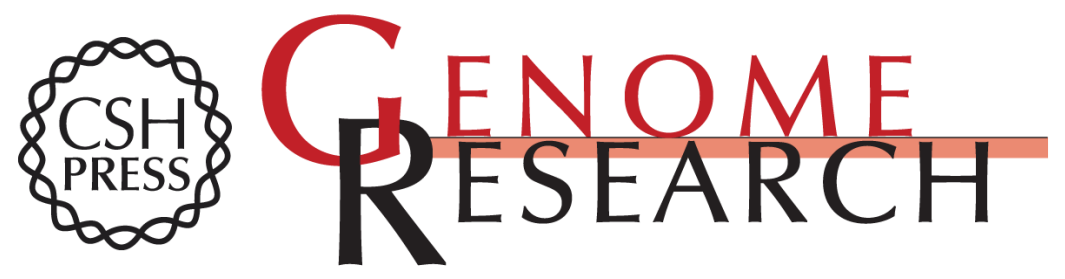

\section{Public Concerns Over Transgenic Crops}

Philip J. Dale

Genome Res. 1999 9: 1159-1162

Access the most recent version at doi:10.1101/gr.9.12.1159

\section{License}

Email Alerting Receive free email alerts when new articles cite this article - sign up in the box at the Service top right corner of the article or click here.

\section{Affordable, Accurate Sequencing.}

To subscribe to Genome Research go to: https://genome.cshlp.org/subscriptions 